Abstracted/indexed in Academic Search Complete, Asia Journals Online, Bangladesh Journals Online, Biological Abstracts, BIOSIS Previews, CAB Abstracts, Current Abstracts, Directory of Open Access Journals, EMBASE/Excerpta Medica, Global Health, Google Scholar, HINARI (WHO), International Pharmaceutical Abstracts, Open J-gate, Science Citation Index Expanded, SCOPUS and Social Sciences Citation Index;

\title{
Volatile phytochemical composition of rhizome of ginger after extraction by headspace solid-phase microextraction, petroleum ether extraction and steam distillation extraction
}

\author{
Zhannan Yang1,2, Weiping Yang1, Quancai Peng'2, Qiansong He', Yong Feng1, Shiqiong \\ Luo $^{2}$ and Zhengwen $\mathbf{Y u}^{2}$
}

${ }^{1}$ Guiyang College of Traditional Chinese Medicine, Guiyang Guizhou 550002, China; ${ }^{2}$ Key Laboratory for Information System of mountainous Area and protection of Ecological Environment of Guizhou Province, Guizhou Normal University, Guiyang Guizhou 550001, China.

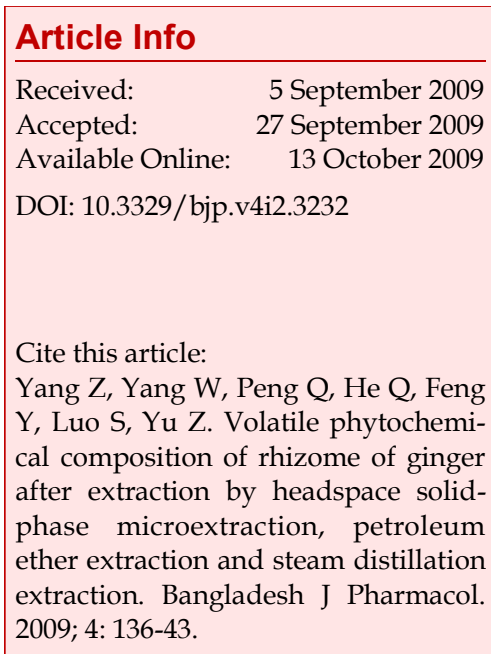

\begin{abstract}
The sampling techniques headspace solid-phase microextraction (HS-SPME), petrol ether extraction (PEE) and steam distillation extraction (SDE) were compared for the GC-MS of volatile constituents present in ginger (Zingiber officinale). The effects of different parameters, such as extraction fibers, extraction time, extraction temperature and particle size ranges, on the HSSPME of rhizome of ginger were investigated. Zingiberene (53.1\%) were predominant components of ginger samples obtained by HS-SPME whereas those levels were $39.0 \%$ in the same samples by PEE and $35.1 \%$ in those by SDE, respectively. HS-SPME with polydimethylsiloxane (PDMS) fiber was more selective and particularly efficient for the isolation of volatile phytochemical composition and afforded a higher yield of total compounds than PEE and SDE. The specific compound isolated by SPME, which due to effective fiber, was much larger than that isolated by PEE or SDE. HS-SPME is a powerful tool for determining the volatile constitutes present in the
\end{abstract}

\section{Introduction}

Traditional Chinese medicines have played an important role in clinical therapy. More and more interests have been re-attracted in recent years for their high pharmacological activity, low toxicity and rare complication (Wen et al., 1993). However, volatile components of traditional Chinese medicines make the isolation and measurement of the volatile constituents as well as quality control of crude drugs and their medical preparations extremely difficult. Traditionally, the analysis of volatile compounds from traditional Chinese medicines is usually preceded by the extraction of essential oil by steam distillation, and/or petrol ether extraction, which often requires a large amount of sample and takes several hours to complete.
The complex and time-consuming process for the preparation of samples sometimes further complicates the analytical results due to more influencing factors involved. Solid-phase microextraction (SPME) developed by Pawliszyn and coworkers in 1989, is a solventless extraction technique widely used in application of extraction from plants, food, biological and environmental samples (Zini et al., 2002; Arthur and Pawliszyn, 1990; Belardi and Pawliszyn, 1989; Cai et al., 2001; Jayatilaka et al., 1995). Headspace solid-phase microextraction (HS-SPME) also is a unique sample preparation technique, which eliminates most draw-backs to extracting organics, including high cost and excessive preparation time; in particular, HS-SPME is a simple and fast modern tool used to characterize the volatile fraction of aromatic and medicinal plants (Smith, 2003; 
Marriott et al., 2001). HS-SPME has diminished decomposition of plant com-pounds and cells, minimized activity of enzyme, and decreasing loss of those constituents. HS-SPME techniques offer a useful alternative to conventional techniques.

Zingiber officinale Rosc. (Zingiberaceae), a member of the tropical and sub-tropical Zingiberaceae, has been cultivated for thousands of years as a spice and for medicinal purposes. It is used extensively in traditional Chinese medicine to treat headaches, nausea and colds and in Ayurvedic and Western herbal medicinal practice for the treatment of arthritis, rheumatic disorders and muscular discomfort (College, 1985). Volatile phytochemical composition of rhizome of ginger were reported (Salgueiro et al., 2003; Maheshwari et al., 1986; Prakash et al., 1993; Meepagala et al., 2002; Bhuiyan et al., 2008), and their main composition is Zingiberene and its derivatives, and compounds of pharmacological activity of ginger are gingerols and its derivatives. If the compositions can reciprocally transform under specific conditions, it is necessary to elucidate biochemical pathways to important compounds, such as the ginger oils, in these plants by GC/MS and HPLC/MS, but sample preparation technique can reflect investigation result of the biochemical pathways of ginger. So, choice of sampling technique also is very important.

In the work discussed in this paper, to enable further understanding of the effects of different parameters, such as extraction fibers, extraction time, extraction temperature and particle size ranges, on HS-SPME of ginger. We compared three different extraction techniques including HS-SPME, petrol ether extraction (PEE) and steam distillation extraction (SDE) for GC-MS of volatile constituents from ginger.

\section{Material and Methods}

Samples of rhizome of ginger were obtained comercially from Shuicheng of Guizhou Province, China. Samples were air dried, ground in a high-speed rotary cutting mill, and then screened to give fractions 40, 80, 120 , and $160 \mu \mathrm{m}$ in size, respectively.

SDE: The essential oil was prepared as follows: $100 \mathrm{~g}$ sample of $120 \mu \mathrm{m}$ particle size was weighted into a 1,000 mL distillation flask, $500 \mathrm{~mL}$ deionised water was added and the mixture was distilled for 4 hours. Oil was collected from the condenser and oil was diluted with $5 \mathrm{~mL}$ of $n$-hexane. Then the extracts were dried with anhydrous sodium sulfate. The essential oil was stored at $-20^{\circ} \mathrm{C}$ until analysis.

\section{Petrol ether extraction (PEE)}

The sample (100 $\mathrm{g}$ of dried materials) was submitted to extract with petrol ether for 72 hours, using Soxhlet extraction method. The volatile distillate was collected over anhydrous sodium sulfate and refrigerated until time of analysis.

\section{HS-SPME fiber screening}

Before carrying out the optimization of the HS-SPME conditions for the analysis of volatile compounds of ginger rhizome, fiber screening was carried out. The silica fibers and the manual HS-SPME holder were purchased from supelco (Bellefonte, PA, USA). Four fibers were tested and compared: polydimethylsiloxane (PDMS, $100 \mu \mathrm{m}$ ), polydimethylsiloxane (PDMS, $7 \mu \mathrm{m}$ ), polyacrylate (PA, $85 \mu \mathrm{m})$, and carboxen-polydimethylsiloxane (CAR/PDMS, $75 \mu \mathrm{m}$ ). The coating of all fibers was $1 \mathrm{~cm}$ long. Before GC-MS analysis, each fiber was conditioned in the injector of the GC system, according to the instructions provided by the manufacturer.

HS-SPME: A $0.1 \mathrm{~g}$ amount of ginger rhizome particle (depending on the experimental design) was hermetically sealed in a $4 \mathrm{~mL}$ screw top amber vial with a polypropylene hole cap and PTFE/silicone septa (supelco, Bellefonte, PA, USA) and in a thermostatic bath at the desired temperature (depending on the experimental design). Then, the SPME device was inserted into the sealed vial by manually penetrating the septum and the fiber (depending on the experimental design) was exposed to the plant material headspace during the extraction time (depending on the experimental design). For the preliminary fiber screening study, experimental conditions were set as Table I. After sampling, the SPME was immediately inserted into the GC injector and the fiber thermally desorbed. A desorption time of $3 \mathrm{~min}$ at $250^{\circ} \mathrm{C}$ was used in splitless mode. Before sampling, each fiber was reconditioned for $5 \mathrm{~min}$ in the GC injector port at $250^{\circ} \mathrm{C}$.

GC/MS: GC-MS analyses were carried out by using a shimazu (Japan) GCMS-QP2010 gas chromatograph mass spectrometer with electron impact ionization mode. With a DB - $5(30 \mathrm{~m} \times 0.25 \mathrm{~mm}$ i.d. $\times 0.25 \mu \mathrm{m})$ column, operating conditions for GC were as follows: helium $(99.9 \%)$ was used as the carrier gas at a constant flow rate of $0.8 \mathrm{~mL} / \mathrm{min}$; temperature of injector $250^{\circ} \mathrm{C}$ and interface $260^{\circ} \mathrm{C}$ and split 1:15. Temperature programming was: $50^{\circ} \mathrm{C}, 5 \mathrm{~min} ; 50-100^{\circ} \mathrm{C}, 3^{\circ} \mathrm{C} / \mathrm{min} ; 100$ $-160^{\circ} \mathrm{C}, 4^{\circ} \mathrm{C} / \mathrm{min} ; 160-220^{\circ} \mathrm{C}, 5^{\circ} \mathrm{C} / \mathrm{min} ; 220^{\circ} \mathrm{C}, 15 \mathrm{~min}$. The mass spectral analyses were performed at $70 \mathrm{eV}$ and ion source temperature $260^{\circ} \mathrm{C}$. For the Kovats index, a standard mixture $\mathrm{C}_{8}$ to $\mathrm{C}_{24}$ was used under the same conditions as the samples.

\section{Qualitative and semi-quantitative analysis}

The volatile substances in ginger rhizome were identified by comparing the retention times of the chromatographic peaks with those of authentic compounds run under the same conditions and by comparing the retention indices (as Kovats indices) with the literature data (Smith and Robinson, 1981; 


\begin{tabular}{|c|c|c|c|c|c|}
\hline \multicolumn{6}{|c|}{ Table I } \\
\hline \multicolumn{6}{|c|}{ Results of orthogonal test L16 (44) } \\
\hline$\#$ & Fibers & $\begin{array}{l}\text { Extraction time } \\
\text { (min) }\end{array}$ & $\begin{array}{l}\text { Extraction tempera- } \\
\text { ture }\left({ }^{\circ} \mathrm{C}\right)\end{array}$ & $\begin{array}{l}\text { Particle size ranges } \\
\text { (Dp) }\end{array}$ & Sum of peak areas \\
\hline 1 & PDMS $7 \mu \mathrm{m}$ & 10 & 50 & 120 & $2.5 \mathrm{E}+8$ \\
\hline 2 & PDMS $7 \mu \mathrm{m}$ & 20 & 40 & 160 & $3.0 \mathrm{E}+8$ \\
\hline 3 & PDMS $7 \mu \mathrm{m}$ & 30 & 80 & 40 & $3.5 \mathrm{E}+8$ \\
\hline 4 & PDMS $7 \mu \mathrm{m}$ & 40 & 60 & 80 & $3.3 \mathrm{E}+8$ \\
\hline 5 & PDMS $100 \mu \mathrm{m}$ & 10 & 40 & 40 & $2.6 \mathrm{E}+8$ \\
\hline 6 & PDMS $100 \mu \mathrm{m}$ & 20 & 50 & 80 & $4.2 \mathrm{E}+8$ \\
\hline 7 & PDMS $100 \mu \mathrm{m}$ & 30 & 60 & 120 & $9.8 \mathrm{E}+8$ \\
\hline 8 & PDMS $100 \mu \mathrm{m}$ & 40 & 80 & 160 & $8.4 \mathrm{E}+8$ \\
\hline 9 & CAR/PDMS $75 \mu \mathrm{m}$ & 10 & 60 & 160 & $0.8 \mathrm{E}+8$ \\
\hline 10 & CAR/PDMS $75 \mu \mathrm{m}$ & 20 & 80 & 120 & $2.1 \mathrm{E}+8$ \\
\hline 11 & CAR/PDMS $75 \mu \mathrm{m}$ & 30 & 40 & 80 & $4.8 \mathrm{E}+8$ \\
\hline 12 & CAR/PDMS $75 \mu \mathrm{m}$ & 40 & 50 & 40 & $2.2 \mathrm{E}+8$ \\
\hline 13 & PA $85 \mu \mathrm{m}$ & 10 & 80 & 80 & $2.7 \mathrm{E}+8$ \\
\hline 14 & PA $85 \mu \mathrm{m}$ & 20 & 60 & 40 & $5.2 \mathrm{E}+8$ \\
\hline 15 & PA $85 \mu \mathrm{m}$ & 30 & 50 & 160 & $3.0 \mathrm{E}+8$ \\
\hline 16 & PA $85 \mu \mathrm{m}$ & 40 & 40 & 120 & $5.6 \mathrm{E}+8$ \\
\hline
\end{tabular}

Kami et al., 1972; MacLeod and Pieris, 1984; Sakamura, 1987; Chyaui et al., 1992; Georgieva et al., 2005; Chen et al., 1986; Bartley et al., 2000; Yang et al., 2009). Peak enrichment on co-injection with authentic reference compounds was also carried out. The comparison of the MS fragmentation pattern with those of pure compounds and mass spectrum database search was performed using the National Institute of Standards and Technology (NIST147) MS spectral database, and Kovats index retention (Chyaui et al., 1992). The relative amounts of individual components are expressed as percent peak areas relative to total peak area.

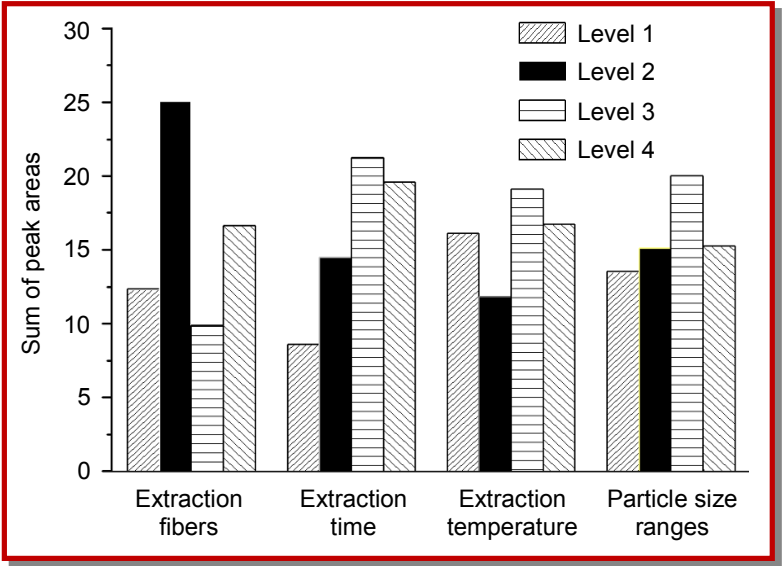

Figure 1: The responses of peak areas under orthogonal conditions (for designations of factors-extraction fibers, extraction time, extraction temperature and particle size ranges)
The ion currents generated depend on the characteristics of the compound and for this reason the quantification was not completely true one. The results obtained by GC/MS might be used for characteristics of the biodiversity in the investigated organisms, as well as for quantitative comparisons between different groups of metabolites in them. This method is suitable for comparing the chemical composition of different organisms, because the deviations caused by the differences in the intensity of the mass spectral fragmentation will be identical (Georgieva et al., 2005).

\section{Precision of HS-SPME}

The precision of HS-SPME was studied with six replicate analyses of the essential oils in Z. officinale under the optimum conditions. The precision was expressed as the relative standard deviation (RSD) of the peak areas.

\section{Results and Discussion}

Since various parameters potentially affect the extraction process, the optimization of the experimental conditions represents a critical step in the development of HS-SPME. In fact, extraction fibers, extraction time, extraction temperature and particle size ranges are generally considered as the most important factors. The optimization of the method can be carried out step-bystep or by using an experimental design. Table I shows different conditions of experiments carried out with HS 


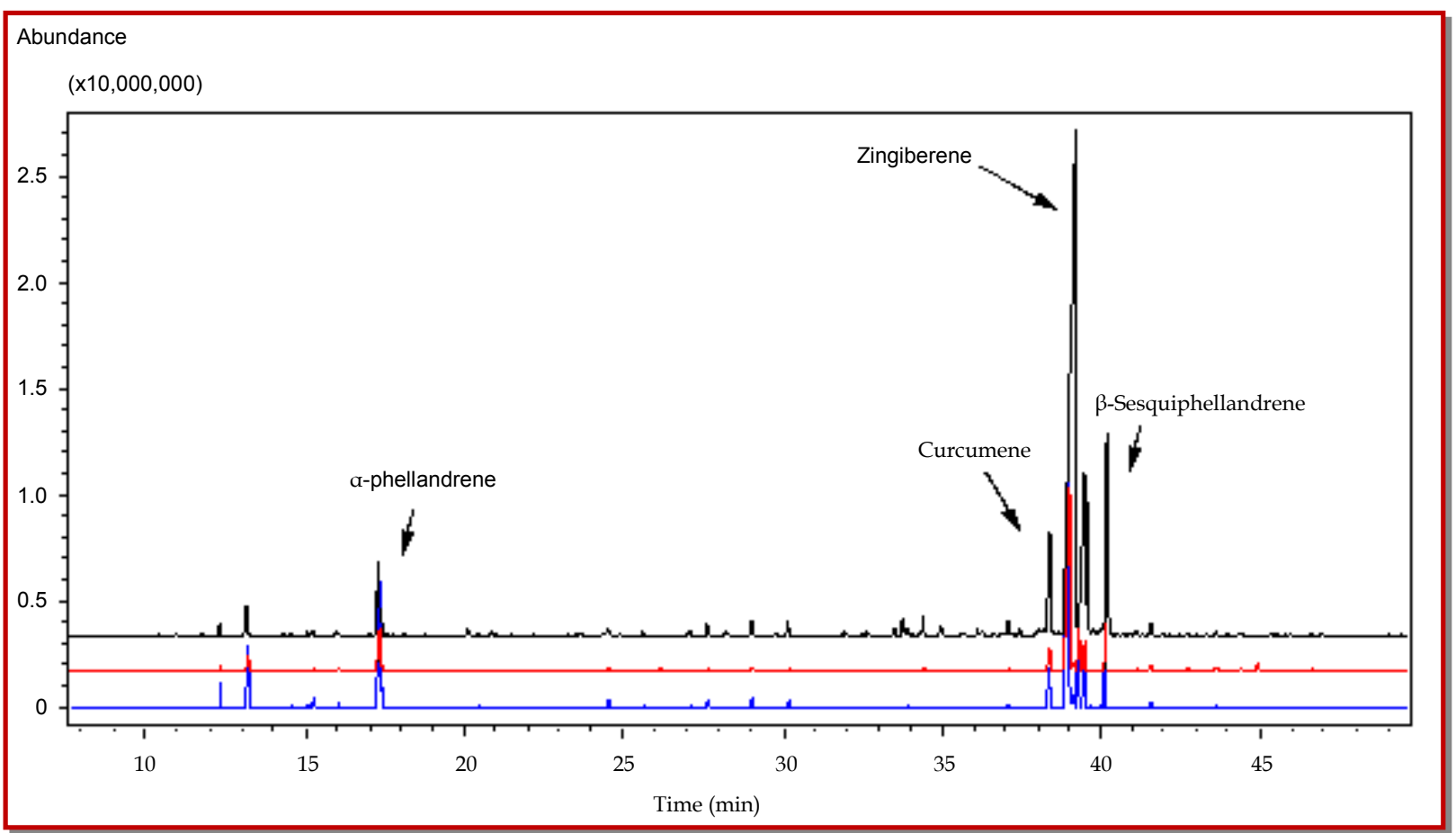

Figure 2: Additional chromatogram of ginger samples of HS-SPME (1), PEE (2) and SDE (3)

-SPME for extractions of ginger. All the selected factors were examined using a four-level orthogonal array design with an $\mathrm{L}_{4} 16\left(4^{4}\right)$ matrix. In general, a full evaluation of the effect of four factors from three levels on the yield needs $256\left(4^{4}\right)$ experiments. In order to reduce the number of experiments, a $\mathrm{L}_{4}\left(4^{4}\right)$ orthogonal design graph was used (Table I).

In this study, interactions among variables were not incorporated in the matrix and focus was placed on the main effects of the four most important factors. The results of the HS-SPME experiments, based on

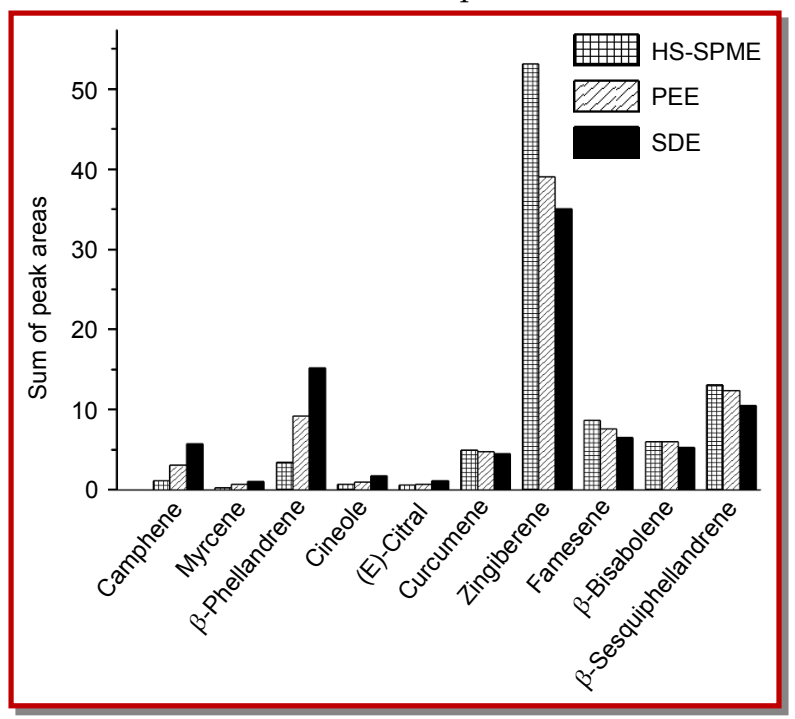

Figure 3: Comparison of the mainly volatile components extracted by SH-SPME, PFE and SDE responses of peak areas, are given in Table I. The influence of the extraction fiber on the composition of the extracts was studied. For all the analytes, the extraction fiber was found to be significant as the main effect. The mean values of the responses of peak areas for the corresponding factors at each level were calculated according to the assignment of the experiment Figure 1. For example, the responses of peak areas of the four trials at PDMS $100 \mu \mathrm{m}$ were evaluated as mean values of the corresponding four runs. The mean values of the four levels of each factor (e.g., extraction fibers) reveal how the responses of peak areas changes when the level of that factor is changed. Figure 1 shows the variations in responses of peak areas as a function of change in different levels of the factors studied. For the complete recovery of the main components of the plant, selective fiber is necessary. This is because different fibers, at constant condition, adsorb different compounds. The influence of extraction temperature on the composition of the extracts was studied. Higher temperature resulted in higher responses of peak areas. But excessively higher extraction temperature reduced extraction efficiency for desorption of part compounds. For all the analytes, the extraction time is the optimal sampling time. The results indicate that the responses of peak areas progressively increase with increasing the extraction time, but no significant increase in the response with farther increasing the extraction time. The influence of the particle size ranges of ginger on the composition of the extracts was studied. Extraction was performed with $40 \mu \mathrm{m}$ of particle size ranges, followed by 80,120 


\begin{tabular}{|c|c|c|c|c|c|c|c|c|}
\hline \multicolumn{9}{|c|}{ Table I } \\
\hline \multicolumn{9}{|c|}{ GC-MS analytical results of ginger obtained by HS-SPME, PEE and SDE } \\
\hline \multirow[t]{2}{*}{$\#$} & \multirow[t]{2}{*}{$\mathrm{T}_{\mathrm{R}}$} & \multirow[t]{2}{*}{$\mathrm{KI}^{\mathrm{a}}$} & \multirow[t]{2}{*}{ Compounds } & \multicolumn{3}{|c|}{$\begin{array}{l}\text { Content of volatile compo- } \\
\text { sition }(\%)\end{array}$} & \multirow{2}{*}{$\begin{array}{c}\text { RSD of HS } \\
\text {-SPME } \\
(\%)\end{array}$} & \multirow[t]{2}{*}{ ID } \\
\hline & & & & HS-SPME & PEE & SD & & \\
\hline 1 & 12.3 & 938 & a-Pinene (ID: KI; 14) & 0.4 & 1.3 & 2.3 & NC & KI; PD \\
\hline 2 & 13.2 & 951 & Camphene (ID: RS=97\%) & 1.1 & 3.0 & 5.7 & 7.1 & MS \\
\hline 3 & 14.3 & 971 & $\begin{array}{l}\text { Bicyclo[3.1.0]hexane,4-methylene-1-(1- } \\
\text { methylethyl) (ID: RS=93\%) }\end{array}$ & - & - & 0.1 & $\mathrm{NC}$ & MS \\
\hline 4 & 14.5 & 976 & 2(10)-Pinene (ID: KI; 15) & - & - & 0.2 & NC & KI; PD \\
\hline 5 & 15.1 & 987 & 6-Methyl-5-hepten-2-one (ID: RS=94\%) & 0.1 & 0.2 & 0.4 & $\mathrm{NC}$ & MS \\
\hline 6 & 15.2 & 990 & Myrcene (ID: KI; 22) & 0.2 & 0.6 & 1.0 & NC & $\mathrm{KI} ; \mathrm{PD}$ \\
\hline 7 & 16.0 & 1007 & a-Phellandrene (ID: 16) & 0.1 & 0.6 & 0.7 & $\mathrm{NC}$ & PD \\
\hline 8 & 17.3 & 1032 & $\beta$-Phellandrene (ID: 16) & 3.3 & 9.1 & 15.1 & 6.6 & PD \\
\hline 9 & 17.4 & 1034 & Cineole (ID: 17) & 0.6 & 0.9 & 1.7 & $\mathrm{NC}$ & PD \\
\hline 10 & 20.1 & 1086 & ND & 0.2 & 0.3 & 0.2 & NC & ND \\
\hline 11 & 20.4 & 1093 & 2-Nonanone (ID: RS=97\%) & 0.1 & 0.1 & 0.3 & $\mathrm{NC}$ & MS \\
\hline 12 & 20.9 & 1100 & Linalol (ID: KI; 22) & 0.1 & 0.2 & 0.3 & NC & $\mathrm{KI} ; \mathrm{PD}$ \\
\hline 13 & 21.0 & 1104 & 2-Heptanol, 6-methyl- (ID: RS=92\%) & - & - & 0.1 & $\mathrm{NC}$ & PD \\
\hline 14 & 23.4 & 1151 & 3,3-Dimethyl-1-octene (ID: RS=93\%) & - & - & 0.1 & $\mathrm{NC}$ & PD \\
\hline 15 & 24.5 & 1176 & Borneol & 0.3 & 0.6 & 0.8 & NC & PD \\
\hline 16 & 24.8 & 1182 & $\begin{array}{l}\text { 3-Cyclohexen-1-ol, 4-methyl-1-(1-methylethyl)- } \\
\text { (ID: RS=91\%) }\end{array}$ & - & - & 0.1 & $\mathrm{NC}$ & PD \\
\hline 17 & 25.6 & 1198 & p-menth-1-en-8-ol (ID: 18; RS=94\%) & 0.1 & 0.3 & 0.4 & NC & MS;PD \\
\hline 18 & 26.1 & 1209 & Caprinaldehyde (ID: RS=94\%) & - & 0.8 & - & NC & MS \\
\hline 19 & 27.1 & 1231 & Citronellol (ID: RS=95\%) & 0.1 & 0.2 & 0.3 & $\mathrm{NC}$ & MS \\
\hline 20 & 27.7 & 1242 & Z-Citral (ID: 18; RS=94\%) & 0.4 & 0.4 & 0.9 & NC & PD;MS \\
\hline 21 & 28.2 & 1255 & Nerol (ID: 19; RS=92\%) & 0.1 & 0.2 & 0.2 & $\mathrm{NC}$ & PD;MS \\
\hline 22 & 29.1 & 1272 & (E)-Citral (ID: RS=95\%) & 0.6 & 0.6 & 1.1 & $\mathrm{NC}$ & MS \\
\hline 23 & 29.8 & 1285 & Bornyl acetate (ID: RS=93\%) & 0.1 & - & 0.1 & $\mathrm{NC}$ & MS \\
\hline 24 & 30.2 & 1293 & 2-Undecanone (ID: RS=95\%) & 0.4 & 0.6 & 0.9 & $\mathrm{NC}$ & MS \\
\hline 25 & 32.0 & 1337 & $\beta$-Elemene (ID: KI; RS=93\%) & 0.1 & - & - & NC & KI; MS \\
\hline 25 & 32.7 & 1352 & Citronellol (ID: RS=94\%) & 0.1 & - & - & $\mathrm{NC}$ & MS \\
\hline 27 & 33.5 & 1372 & (+)-Cycloisosativene (ID: KI; RS=93\%) & 0.3 & 0.2 & 0.2 & NC & KI; MS \\
\hline 28 & 33.8 & 1379 & Copaene (ID: 20; KI) & 0.6 & 0.4 & 0.3 & NC & $\mathrm{KI} ; \mathrm{PD}$ \\
\hline 29 & 33.9 & 1381 & Geraniol acetate( ID: RS=96\%) & 0.3 & 0.1 & 0.2 & $\mathrm{NC}$ & MS \\
\hline 30 & 34.4 & 1393 & $\begin{array}{l}\text { 2,4-Diisopropenyl-1-methyl-1-vinylcyclohexane } \\
\text { (ID: RS=96\%) }\end{array}$ & 0.8 & 0.4 & 0.3 & NC & MS \\
\hline 31 & 34.9 & 1405 & ND & 0.3 & 0.2 & 0.2 & NC & ND \\
\hline 32 & 35.7 & 1423 & ND & 0.1 & - & - & $\mathrm{NC}$ & ND \\
\hline 33 & 36.1 & 1433 & ү-Elemene (ID: KI; 21) & 0.3 & - & - & $\mathrm{NC}$ & KI; PD \\
\hline 34 & 36.3 & 1436 & ND & 0.1 & - & 0.1 & $\mathrm{NC}$ & ND \\
\hline 35 & 36.9 & 1451 & ND & 0.1 & - & 0.1 & NC & ND \\
\hline 36 & 37.1 & 1456 & $\begin{array}{l}\text { 1,6,10-Dodecatriene, 7,11-dimethyl-3-methylene- } \\
\text { (ID: RS=94\%) }\end{array}$ & 0.7 & 0.5 & 0.5 & $\mathrm{NC}$ & MS \\
\hline 37 & 37.4 & 1464 & Aromadendrene (ID: KI; 20) & 0.2 & 0.2 & 0.1 & NC & $\mathrm{KI} ; \mathrm{PD}$ \\
\hline
\end{tabular}




\begin{tabular}{|c|c|c|c|c|c|c|c|c|}
\hline \multicolumn{9}{|c|}{ Table II } \\
\hline \multicolumn{9}{|c|}{ GC-MS analytical results of ginger obtained by HS-SPME, PEE and SDE } \\
\hline \multirow[t]{2}{*}{$\#$} & \multirow[t]{2}{*}{$\mathrm{T}_{\mathrm{R}}$} & \multirow[t]{2}{*}{ KIa } & \multirow[t]{2}{*}{ Compounds } & \multicolumn{3}{|c|}{$\begin{array}{l}\text { Content of volatile compo- } \\
\text { sition }(\%)\end{array}$} & \multirow{2}{*}{$\begin{array}{c}\text { RSD of } \\
\text { HS-SPME } \\
(\%)\end{array}$} & \multirow[t]{2}{*}{ ID } \\
\hline & & & & HS-SPME & PEE & SD & & \\
\hline 38 & 38.0 & 1478 & Chamigrene (ID: RS = 95\%) & 0.2 & - & - & $\mathrm{NC}$ & MS \\
\hline 39 & 38.2 & 1482 & ND & 0.2 & - & - & NC & ND \\
\hline 40 & 38.4 & 1487 & Curcumene (ID:17) & 4.9 & 4.7 & 4.5 & 6.2 & PD \\
\hline 41 & 38.5 & 1490 & ND & 0.2 & 0.2 & - & NC & ND \\
\hline 42 & 38.7 & 1494 & $\beta$-Eudesmene (ID: RS $=94 \%$ ) & 0.1 & 0.1 & 0.2 & NC & MS \\
\hline 43 & 39.2 & 1507 & Zingiberene (ID: 16; 17) & 53.1 & 39.0 & 35.1 & 3.6 & PD \\
\hline 44 & 39.5 & 1514 & Farnesene (ID: 16; 17) & 8.6 & 7.6 & 6.5 & 4.7 & PD \\
\hline 45 & 39.6 & 1517 & $\beta$-Bisabolene (ID: 16; 17) & 6.0 & 5.9 & 5.2 & 5.8 & PD \\
\hline 46 & 39.7 & 1521 & ND & 0.3 & 0.3 & 0.2 & NC & ND \\
\hline 47 & 39.9 & 1526 & $(+)$-Cadinene (ID: RS = 96\%) & 0.2 & 0.3 & 0.2 & NC & MS \\
\hline 48 & 40.3 & 1534 & $\beta$-Sesquiphellandrene (ID: 23) & 13.0 & 12.3 & 10.4 & 5.1 & PD \\
\hline 49 & 41.1 & 1555 & ND & 0.1 & 0.3 & 0.1 & NC & ND \\
\hline 50 & 41.3 & 1560 & ND & 0.1 & 0.2 & 0.1 & NC & ND \\
\hline 51 & 41.5 & 1566 & a-Selinene (ID: RS = 95\%) & 0.5 & 1.0 & 0.8 & NC & MS \\
\hline 52 & 42.7 & 1596 & ND & 0.1 & 0.4 & 0.2 & NC & ND \\
\hline 53 & 43.6 & 1620 & ND & 0.1 & 0.7 & 0.3 & NC & ND \\
\hline 54 & 43.9 & 1627 & $\beta$-Cadin-4-en-10-ol (ID: RS = 93\%) & - & 0.2 & - & NC & MS \\
\hline 55 & 44.4 & 1638 & Caryophyllene (ID: RS = 92\%) & 0.1 & 0.5 & 0.2 & NC & MS \\
\hline 56 & 44.8 & 1649 & Zingiberone (ID: 18) & - & 1.2 & - & NC & PD \\
\hline 57 & 45.3 & 1662 & $\beta$-Eudesmol (ID: RS = 95\%) & - & 0.3 & 0.1 & NC & MS \\
\hline 58 & 46.6 & 1693 & trans-a-Bergamotene (ID: RS = 96\%) & 0.1 & 0.8 & 0.2 & NC & MS \\
\hline 59 & 46.9 & 1703 & $\begin{array}{l}\text { 4-(2,2-Dimethyl-6-methylenecyclohexyl)butanal } \\
\text { (ID: RS }=95 \%)\end{array}$ & - & 0.3 & - & NC & MS \\
\hline
\end{tabular}

and $160 \mu \mathrm{m}$ of particle size ranges. Results showed that $120 \mu \mathrm{m}$ of particle size ranges enhanced the extraction of the most responses of peak areas. Thus, the best conditions, obtained by preliminary test, for the HSSPME were: extraction fiber: polydimethylsiloxane (PDMS, $100 \mu \mathrm{m}$ ); extraction temperature: $60^{\circ} \mathrm{C}$; extraction time: $30 \mathrm{~min}$; particle size ranges: $120 \mu \mathrm{m}$. The product of No. 7 orthogonal test was analyzed by GC-MS.

The GC-MS profiles of HS-SPME, PEE, and SDE were Figure 2a. Detailed identification and quantization of the compounds found in, produced by HS-SPME under No. 7 orthogonal test conditions were performed by GC -MS, as shown in Table II. Product obtained by PEE and SDE were also analyzed by GC-MS, respectively. The results are also shown in Table II for comparison. The volatile phytochemical composition of $Z$. officinale by HS-SPME (No. 7) was analysed by GC-MS, and camphene $(1.1 \%)$, myrcene $(0.2 \%) \beta$-phellandrene $(3.3 \%)$, curcumene $(4.9 \%)$, zingiberene $(53.1 \%)$, farnesene $(8.6 \%), \beta$-bisabolene $(6.0 \%)$, and $\beta$-sesquiphellandrene $(13.0 \%)$ were the major compounds; camphene $(3.0 \%)$, myrcene $(0.6 \%), \quad \beta$-phellandrene $(9.1 \%)$, curcumene
$(4.7 \%)$, zingiberene $(39.0 \%)$, farnesene $(7.6 \%), \beta$-bisabolene $(5.9 \%)$, and $\beta$-sesquiphellandrene $(13.0 \%)$ were the major compounds by gas chromatographic analyses from PEE; camphene $(5.7 \%)$, myrcene $(1.0 \%), \beta$-phellandrene $(15.1 \%)$, cineole $(1.7 \%)$, (E)-citral $(1.1 \%)$, curcumene $(4.5 \%)$, zingiberene $(35.1 \%)$, farnesene $(6.5 \%), \beta$ bisabolene $(5.2 \%)$, and $\beta$-sesquiphellandrene $(10.4 \%)$ were the major compounds by gas chromatographic analyses from SDE; volatile phytochemical composition rhizome of ginger were monoterpenes and sesquiterpene.

Different methods of natural products extraction yield different efficiencies; Figure 2 shown by the results, the content of composition of the HS-SPME, PEE and SDE of rhizome of ginger were different. By comparing the composition of the HS-SPME product with the PEE and SDE, higher levels of sesquiterpene were found in the HS-SPME and higher levels of monoterpenes were found in the SFE and PEE. Table I showed that zingiberene content of the HS-SPME is considerable and the relative percentage of zingiberene is $53.1 \%$. However, the relative percentage of zingiberene this compound 
was 39.0 and $35.1 \%$, respectively. On the other hand, Figure 3 showed that, for main monoterpenes (e.g., camphene, myrcene, and $\beta$-Phellandrene), the HSSPME always is lowest, and the PEE is always lower, and the SDE is always highest. For example, $\beta$-phellandrene of the HS-SPME, the PEE and the SDE was 3.3, 9.1 and $15.1 \%$, respectively. By contraries, for main sesquiterpene (curcumene, zingiberene, farnesene, $\beta$ bisabolene, and $\beta$-sesquiphellandrene) the HS-SPME always is highest, and the PEE is always lower, and the SDE is always lowest. For example, zingiberene of the HS-SPME, the PEE and the SDE was 53.1, 39.0 and $35.1 \%$, respectively. The results were different from each other by because of the different methods of HSSPME, PEE, and SDE in dealing with the extract, which can due to more influencing factors involved. For examples, fiber material of HS-SPME straightly influences adsorption of compound species, and temperature also influences equilibrium of adsorption and desorption of compounds.

Choosing a fiber with suitable polarity, depending on the nature of the target compounds, is a very important factor in headspace analysis. In this work, the most effective fiber for HS-SPME was PDMS. The effects of different parameters on the HS-SPME sampling from rhizome of ginger were also studied. The results showed that sampling temperature is the dominant factor for the HS-SPME of the volatile compounds of rhizome of ginger; this could be due to an increase in less volatile compounds in the headspace which might compensate for the decrease in adsorption induced by high temperatures. The complex and time-consuming process for the preparation of PEE and SDE sometimes further complicates the analytical results due to more influencing factors involved.

The HS-SPME-GC-MS method, developed and applied in this work, proved to be a simple, speed and convenient tool for the purpose of fingerprinting characteristic of the volatile composition of traditional Chinese medicines. Large amounts of sesquiterpenes and lesser amounts of monoterpenes are responsible for the characteristic aroma of ginger. The qualitative profile of the volatile compounds of rhizome of ginger was similar, but their relative abundance showed several differences. This work is a first step which opens the perspective of further studies on the aroma composition of rhizome of ginger.

\section{Conclusion}

HS-SPME followed by GC-MS is suited to the extraction and semi-quantitative analysis of volatiles from rhizome of ginger.

\section{Acknowledgement}

This research work was financially supported by the National Basic Research Program (973 program) 2007CB512606. The language edited was revised by International Science Editing.

\section{References}

Arthur CL, Pawliszyn J. Solid phase-with thermal desorption using fused silica optical fibers. Anal Chem. 1990; 62: 214548.

Bartley JP, Jacobs AL. Effects of drying on flavour compounds in Australian-grown ginger (Zingiber officinale). J Sci Food Agr. 2000; 80: 209-15.

Belardi RP, Pawliszyn J. The application of chemically modified fused silica fibers in the extraction of organics from water matrix samples and their rapid transfer to capillary columns. Water Pollut Res J Can. 1989; 24: 179-91.

Bhuiyan MNI, Chowdhury JU, Begum J. Volatile constituents of essential oils isolated from leaf and rhizome of Zingiber cassumunar Roxb. Bangladesh J Pharmacol. 2008; 3: 69-73.

Cai J, Liu B, Su Q. Comparison of simultaneous distillation extraction and solid-phase microextraction for the determination of volatile flavor components. J Chromatogr. A. 2001; 930: 1-7.

Chen C, Kuo M, Wu C, Ho C. Pungent compounds of ginger (Zingiber officinale roscoe) extracted by liquid carbon dioxide. J Agric Food Chem. 1986; 34: 477-80.

Chyaui CC, Chen S, Wu M. Differences of volatile and nonvolatile constituents between mature and ripe guava (Psidium guajava Linn.) fruits. J Agric Food Chem. 1992; 40: 846-49.

College JNM. The dictionary of traditional Chinese medicine. Shanghai, Shanghai Sci-Tech Press, 1985, pp 205-07.

Georgieva E, Handjieva N, Popov S, Evstatieva L. Comparative analysis of the volatiles from flowers and leaves of three Gentiana species. Biochem Syst Ecol. 2005; 33: 938-47.

Jayatilaka A, Poole SK, Poole CF, Chinchila TMP. Simultaneous micro steam distillation/solvent extraction for the isolation of semivolatile flavor compounds from cinnamon and their separation by series coupled-column gas chromatography. Anal Chim Acta. 1995; 302: 147-62.

Kami T, Nakayama M, Hayashi S. Volatile constituents of Zingiber officinale. Phytochemistry 1972; 11: 3377-81.

MacLeod AJ, Pieris NM. Volatile aroma constituents of Sri Lankan ginger. Phytochemistry 1984; 23: 353-59.

Maheshwari JK, Kalakoti BS, Lal B. Ethnomedicine of Bhil tribe of Jhabua District. Ancient Sci Life. 1986; 5: 255-61.

Marriott PJ, Shellie R, Cornwell C. Gas chromatographic technologies for the analysis of essential oils. J Chromatogr A. 2001; 936: 1-22.

Meepagala KM, Sturtz G, Wedge DE. Antifungal constituents 
of the essential oil fraction of Artemisia dracunculus L. Var. dracunculus. J Agric Food Chem. 2002; 50: 6989-92.

Prakash AO, Sisodia B, Mathur R. Antifertility efficacy of some indigenous plants in female rats. Indian Drugs. 1993; 30: 1925.

Sakamura F. Changes in volatile constituents of Zingiber officinale rhizomes during storage and cultivation. Phytochemistry 1987; 26: 2207-12.

Salgueiro LR, Cavaleiro C, Pinto E, Pina-Vaz C, Rodrigues AG, Palmeira A, Tavares C, Costa-de-Oliveira S, Gonçalves MJ, Martinez-de-Oliveira J. Chemical composition and antifungal activity of the essential oil of Origanum virens on Candida species. Planta Med. 2003; 69: 871-74.

Smith RM, Robinson JM. The essential oil of ginger from Fiji. Phytochemistry 1981; 20: 203-06.
Smith RM. Before the injection-modern methods of sample preparation for separation techniques. J Chromatogr A. 2003; 1000: 3-27.

Wen KC, Huang CY, Lu FL. Determination of baicalin and puerarin in traditional Chinese medicinal preparations by high-performance liquid chromatography. J Chromatogr A. 1993; 631: 241-50.

Yang Z, Luo S, Peng Q, Zhao C, Yu Z. GC-MS analysis of the essential oil of coral ginger (Zingiber corallinum Hance) rhizome obtained by supercritical fluid extraction (SFE) and steam distillation extraction (SDE). Chromatographia 2009; 69: 785-90.

Zini CA, Lprd H, Christensen E, Assis TF, Caramao EB, Pawliszyn J. Automation of solid-phase microextraction-gas chromatography-mass spectrometry extraction of eucalyptus volatiles. J Chromatogr Sci. 2002; 40: 140-46. 